\title{
Promosi Kesehatan "Sadari" Menggunakan Instagram pada Mahasiswi Non Kesehatan Universitas Andalas
}

\author{
Health Promotion Breast Self Examination (BSE) Using Instagram in Non \\ Medical Student of Andalas University
}

\author{
Ayulia Fardila Sari ZA*, Nengsih Purnama Sari, Nabila \\ Universitas Andalas \\ (*ayuliafardila@gmail.com)
}

\begin{abstract}
ABSTRAK
Angka kejadian kanker payudara di Provinsi Sumatera Barat menempati urutan ketiga dari 34 provinsi di Indonesia, dengan estimasi jumlah penderita kanker payudara sebanyak 2.285 orang. Berdasarkan studi awal, diperoleh 18 dari 30 orang mahasiswi mengetahui istilah upaya deteksi dini Pemeriksaan Payudara Sendiri (Sadari), tetapi 14 orang belum pernah melakukannya. Inovasi promosi kesehatan yang melibatkan pemanfaatan sosial media Instagram diperlukan untuk meningkatkan pengetahuan, sikap, dan persepsi kegunaan teknologi dalam menekan angka kejadian kanker payudara. Tujuan dari penelitian ini adalah untuk mengukur pengaruh promosi kesehatan Sadari melalui media sosial Instagram terhadap peningkatan pengetahuan, sikap, dan persepsi kegunaan teknologi pada mahasiswi non kesehatan Universitas Andalas. Penelitian ini merupakan quasi eksperiment dengan pendekatan non equivalent pre test post test design. Sampel pada penelitian ini adalah mahasiswi fakultas Non-Kesehatan Universitas Andalas dengan jumlah 61 orang. Hasil penelitian terdapat perbedaan skor rata-rata pengetahuan, sikap, dan persepsi kegunaan teknologi responden sebelum dan sesudah promosi kesehatan Sadari ( $p$ value $<0,05$ ) serta Instagram dapat memberikan kemudahan pada pengguna dalam melakukan penyebaran informasi kesehatan secara visual seluas mungkin dengan tampilan yang menarik.
\end{abstract}

Kata kunci : Promosi kesehatan, sadari, instagram

\section{ABSTRACT}

The incidence of breast cancer in West Sumatra Province ranks third out of 34 provinces in Indonesia, with an estimated number of 2,285 breast cancer patients. Based on the initial study, 18 out of 30 female students learned about the term Breast Self Examination (BSE), but 14 people have never done BSE. Health promotion innovation efforts involving the use of social media Instagram is needed to improve knowledge, attitudes, and perceptions of the usefulness of technology in reducing the incidence of breast cancer. The purpose of this study is to measure the effect of BSE health promotion through Instagram social media on increasing knowledge, attitudes, and perceptions of the usefulness of technology in Andalas University students. The type of research is quasi experiment with a non equivalent pretest post test design approach. The sample in this research are non medical student of Andalas University amounted to 61 people. The result of the research, there was differences in the average score of knowledge, attitudes, and perceptions of the usefulness of the respondents technology before and after BSE health promotion using Instagram social media ( $p$ value $<0.05$ ) and Instagram can provide convenience to users in disseminating health information visually as widely as possible with an attractive appearance.

Keywords : Health promotion, BSE, instagram

Copyright (C) 2019 by author. This is an open access article under the CC BY-NC-SA license

(https://creativecommons.org/licenses/by-nc-sa/4.0/).

DOI : http://dx.doi.org/10.30597/mkmi.v15i3.6270 


\section{PENDAHULUAN}

Kanker payudara adalah tumor ganas yang tumbuh di dalam jaringan payudara. Kanker tersebut bisa mulai tumbuh di dalam kelenjar susu, saluran susu, jaringan lemak maupun jaringan ikat payudara. ${ }^{1}$ WHO menyatakan bahwa kanker payudara adalah kanker yang paling sering terjadi di kalangan wanita. Tahun 2018, kanker payudara menempati peringkat pertama kasus kanker pada wanita, yaitu sebesar $24,2 \%$ dari total kasus kanker. Kanker payudara juga menjadi penyebab kematian tertinggi akibat kanker pada wanita, yaitu sebesar $15 \% .{ }^{2}$ Data Kementerian Kesehatan RI 2017, kanker payudara masih menjadi kasus yang tertinggi di Indonesia yaitu 42,1 per 100.000 penduduk dengan rata-rata kematian 17 per 100.000 penduduk yang diikuti kanker leher rahim sebesar 23,4 per 100.000 penduduk dengan rata-rata kematian 13,9 per 100.000 penduduk. Angka kejadian kanker payudara di Provinsi Sumatera Barat menempati urutan ketiga dari 34 provinsi setelah DI Yogyakarta dan Kalimantan Timur yaitu sebesar $0,9 \%$ dengan estimasi jumlah penderita kanker payudara sebanyak 2.285 orang. ${ }^{3}$ Data RSUP dr. M.Djamil Kota Padang, prevalensi kasus kanker payudara mengalami peningkatan tahun 2010 ke 2013, yaitu 134 kasus menjadi 669 kasus. Jumlah ini terbanyak di Sumatera Barat. ${ }^{4}$

Mayoritas kanker payudara di Indonesia ditemukan pada stadium lanjut ketika peluang mencapai kesembuhan kecil. Prognosis kanker payudara per stadium yaitu stadium I $(100 \%)$, stadium II $(92 \%)$, stadium III $(72 \%)$, dan stadium IV (22\%). Lebih dari 80\% kasus ditemukan berada pada stadium lanjut. Sebanyak $60-70 \%$ pasien kanker payudara berobat pertama kali pada stadium III dan IV. Padahal peluang pasien kanker payudara mencapai kesembuhan mencapai $98 \%$ bila terdeteksi dini dan diobati secara medis. ${ }^{5}$ Gejala kanker payudara stadium awal bisa dideteksi dengan mudah. Sadari adalah pemeriksaan payudara sendiri untuk dapat menemukan adanya benjolan abnormal. Pemeriksaan ini dapat dilakukan sendiri tanpa harus dibantu oleh petugas kesehatan dan tanpa harus mengeluarkan biaya. Para ahli kesehatan dan para penggiat Breast Cancer Awarenes menyarankan agar wanita sebaiknya melakukan pemeriksaan payudara sendiri walau tidak dijumpai. ${ }^{6}$
Instagram merupakan sebuah aplikasi media sosial berbagi foto dan video yang memungkinkan pengguna mengambil foto, menerapkan filter digital dan membagikannya ke berbagai layanan jejaring sosial termasuk instagram sendiri. Tidak kurang dari 45 juta orang Indonesia menggunakan instagram secara aktif, serta tercatat sebagai pembuat konten instagram story terbanyak di dunia. Jumlah ini meningkat dibandingkan jumlah pengguna aktif di awal tahun 2016 hanya 22 juta. Indonesia menjadi komunitas Instagram terbesar di Asia Pasifik, serta salah satu pasar terbesar di dunia dari total 700 juta pengguna aktif setiap bulan.,

Penelitian promosi kesehatan menggunakan media sosial instagram sudah pernah dilakukan oleh peneliti terdahulu. Penelitian yang dilakukan Sari terkait promosi kesehatan tentang Dagusibu (Cara Tepat Penggunaan Obat) melalui media sosial instagram pada mahasiswa Universitas $\mathrm{Mu}-$ hammadiyah Purwokerto. Hasilnya terjadi peningkatan pengetahuan mahasiswa dengan $\mathrm{p}$ value $0,002(p<0,05)$ setelah dilakukan intervensi berupa promosi kesehatan. ${ }^{8}$ Begitu juga penelitian Althunayan et al menyatakan bahwa lebih dari 50\% responden yang menerima pesan promosi kesehatan melalui instagram memiliki sikap yang positif. ${ }^{9}$ Sejalan dengan itu, hasil penelitian Alessandro et al menyimpulkan bahwa promosi kesehatan tentang pemberian Air Susu Ibu (ASI) pada bayi melalui media sosial instagram mampu mengubah persepsi dan membangun dukungan kelompok untuk ibu menyusui di Kanada. ${ }^{10}$ Berbagai penelitian tersebut belum ada yang meneliti terkait pemanfaatan media sosial instagram dalam pencegahan kanker payudara melalui aktifitas Sadari. Begitu juga dengan belum adanya pengukuran tentang variabel persepsi pemanfaatan penggunaan teknologi instagram sebagai media promosi kesehatan.

Universitas Andalas (Unand) adalah Perguruan Tinggi Negeri tertua dan terbesar di Sumatera Barat. ${ }^{11}$ Hasil studi pendahuluan terhadap mahasiswi pada dua fakultas non kesehatan dengan jumlah mahasiswi terbanyak, yaitu Fakultas Ekonomi dan Fakultas Pertanian, diperoleh 18 dari 30 orang mengetahui istilah Sadari namun 14 orang belum pernah melakukan Sadari. Selain itu diketahui bahwa seluruh responden 
memiliki akun media sosial instagram dan sering mengaksesnya. Oleh sebab itu, penulis tertarik untuk meneliti pengaruh promosi kesehatan "Sadari" menggunakan media sosial instagram pada mahasiswi non kesehatan Universitas Andalas tahun 2018.

\section{BAHAN DAN METODE}

Penelitian ini merupakan penelitian analitik dengan design quasi eksperiment pendekatan non equivalent pre test post test design yang dilaksanakan pada bulan Juni sampai dengan Oktober 2018. Lokasi yang digunakan kampus Universitas Andalas, Kota Padang, Sumatera Barat. Populasi pada penelitian ini adalah mahasiswi non kesehatan Universitas Andalas yang terdaftar pada Semester Ganjil tahun ajaran 2017/2018. Alasan pemilihan dua fakultas yaitu fakultas ekonomi dan pertanian tersebut adalah karena memiliki jumlah mahasiswi terbanyak. Fakultas yang dipilih berasal dari bidang non kesehatan untuk meminimalkan bias apabila selama intervensi responden mendapatkan informasi mengenai Sadari dari bangku kuliah. Penarikan sampel dalam penelitian ini menggunakan proporsi sampling dengan kriteria inklusi yang meliputi mahasiswi aktif yang menggunakan instagram, mengisi kuesioner pretest dan posttest penelitian dan bersedia mengikuti (follow) akun instagram yang dibuat khusus untuk penelitian selama penelitian berlangsung. Jumlah sampel yang digunakan pada penelitian ini sebanyak 61 orang yang dihitung dengan menggunakan rumus uji hipotesis beda rata-rata berpasangan. Proses pengambilan sampel di lapangan dengan teknik accidental sampling, mengambil responden yang kebetulan ada atau tersedia di suatu tempat sesuai dengan konteks penelitian serta memenuhi kriteria inklusi dan eksklusi.

Teknik pengumpulan data dalam penelitian ini adalah dengan menggunakan data primer dan data sekunder. Data sekunder berupa jumlah mahasiswi pada masing-masing fakultas di Universitas Andalas, sedangkan data primer berupa kuesioner berbentuk angket mengenai tingkat pengetahuan mengenai Sadari, sikap terhadap Sadari, dan persepsi kegunaan teknologi. Pengukuran pengetahuan terkait tingkat pemahaman responden mengenai ciri-ciri dan pencegahan kanker payudara, definisi Sadari, waktu melakukan Sadari, teknik
Sadari, dan pentingnya Sadari yang terdiri dari 10 pertanyaan, Pengukuran sikap terkait tanggapan responden mengenai Sadari dalam bentuk jawaban sangat setuju, setuju, kurang setuju, tidak setuju, dan sangat tidak setuju sebanyak 11 pertanyaan. Pengukuran persepsi kegunaan teknologi terkait pandangan responden mengenai kemudahan dan kemanfaatan instagram sebagai media promosi kesehatan yang berjumlah 10 pertanyaan.

Data dalam penelitian ini dilakukan uji normalitas terlebih dahulu menggunakan uji Kolmogorov-Smirnov. Hasilnya data tidak terdistribusi normal sehingga menggunakan uji Wilcoxon. Uji Wilcoxon untuk mengukur perbedaan pengetahuan, sikap, dan persepsi kegunaan teknologi sebelum

\section{Tabel 1. Karakteristik Responden}

\begin{tabular}{lcc}
\hline \multicolumn{1}{c}{ Karakteristik } & n & $\mathbf{\%}$ \\
\hline Angkatan & & \\
2013 & - & - \\
2014 & - & - \\
2015 & 4 & 6,6 \\
2016 & 6 & 9,8 \\
2017 & 20 & 32,8 \\
2018 & 31 & 50,8 \\
Umur & & \\
16-20 tahun & 58 & 95,1 \\
$21-25$ tahun & 3 & 4,9 \\
Fakultas & & \\
Ekonomi & 34 & 55,7 \\
Pertanian & 27 & 44,3 \\
Program Studi & & \\
Agribisnis & 22 & 36,1 \\
Agroteknologi & 1 & 1,6 \\
Akuntansi & 26 & 42,6 \\
Akuntansi Internasional & - & - \\
Ekonomi Pembangunan & 3 & 4,9 \\
Ilmu Ekonomi & 2 & 3,3 \\
Manajemen & 1 & 1,6 \\
Kesekretariatan & 2 & 3,3 \\
Penyuluh Pertanian & - & - \\
Proteksi Tanaman & 4 & 6,6 \\
Mulai Menggunakan Media & & \\
Sosial & & \\
2010 & 1 & 1,6 \\
2012 & 3 & 4,9 \\
2013 & 8 & 13,1 \\
2014 & 12 & 19,7 \\
2015 & 16 & 26,2 \\
2016 & 14 & 23,1 \\
2017 & 6 & 9,8 \\
2018 & 1 & 1,6 \\
\hline & & \\
& &
\end{tabular}


Tabel 2. Distribusi Frekuensi Tingkat Pengetahuan Responden Sebelum dan Sesudah Promosi Kesehatan Menggunakan Instagram

\begin{tabular}{|c|c|c|c|c|c|c|c|c|c|}
\hline \multirow{3}{*}{ No. } & \multirow{3}{*}{ Pertanyaan } & \multicolumn{4}{|c|}{ Pre test } & \multicolumn{4}{|c|}{ Post test } \\
\hline & & \multicolumn{2}{|c|}{ Benar } & \multicolumn{2}{|c|}{ Salah } & \multicolumn{2}{|c|}{ Benar } & \multicolumn{2}{|c|}{ Salah } \\
\hline & & $\mathrm{n}$ & $\%$ & $\mathbf{n}$ & $\%$ & $\mathrm{n}$ & $\%$ & $\mathbf{n}$ & $\%$ \\
\hline 1. & $\begin{array}{lrr}\text { Bahan } & \text { makanan } & \text { yang } \\
\text { dapat mengurangi } & \text { kadar } \\
\text { karsinogenik penyebab kanker } \\
\text { adalah ... }\end{array}$ & 42 & 68,9 & 19 & 31,1 & 37 & 60,7 & 24 & 39,3 \\
\hline 2. & $\begin{array}{l}\text { Ukuran tumor sebesar } 2-3 \\
\mathrm{~cm} \text { termasuk ciri-ciri kanker } \\
\text { payudara stadium .. }\end{array}$ & 39 & 63,9 & 22 & 36,1 & 41 & 67,2 & 20 & 32,3 \\
\hline 3. & $\begin{array}{l}\text { Menurut saudari, apakah yang } \\
\text { dimaksud dengan Sadari? }\end{array}$ & 27 & 44,3 & 34 & 55,7 & 44 & 72,1 & 17 & 27,9 \\
\hline 4. & $\begin{array}{l}\text { Bagi wanita yang haid } \\
\text { pemeriksaan payudara sendiri } \\
\text { (Sadari) dapat dilakukan sejak? }\end{array}$ & 26 & 42,6 & 35 & 57,4 & 40 & 65,5 & 21 & 34,4 \\
\hline 5. & $\begin{array}{l}\text { Menurut saudari, bagi wanita } \\
\text { yang telah berhenti haid } \\
\text { (menopause) kapan sebaiknya } \\
\text { melakukan Sadari? }\end{array}$ & 47 & 77,0 & 14 & 23,0 & 51 & 83,6 & 10 & 16,4 \\
\hline 6. & $\begin{array}{l}\text { Teknik yang dilakukan saat } \\
\text { SADARI adalah... }\end{array}$ & 54 & 88,5 & 7 & 11,5 & 43 & 70,5 & 18 & 29,5 \\
\hline 7. & $\begin{array}{l}\text { Saat memeriksa puting } \\
\text { payudara, digunakan ibu jari } \\
\text { dan telunjuk untuk memencet } \\
\text { puting, hal ini bertujuan untuk } \\
\text { memeriksa }\end{array}$ & 33 & 54,1 & 28 & 45,9 & 49 & 80,3 & 12 & 19,7 \\
\hline 8. & Posisi melakukan Sadari & 39 & 63,9 & 22 & 36,1 & 40 & 65,6 & 21 & 34,4 \\
\hline 9. & $\begin{array}{l}\text { Bagaimanakah teknis } \\
\text { pelaksanaan Sadari? }\end{array}$ & 58 & 95,1 & 3 & 4,9 & 58 & 95,1 & 3 & 4,9 \\
\hline 10. & $\begin{array}{l}\text { Mengapa Sadari setiap bulan } \\
\text { sangat penting dilakukan } \\
\text { secara teratur? }\end{array}$ & 46 & 75,4 & 15 & 24,6 & 47 & 77,0 & 14 & 23,0 \\
\hline
\end{tabular}

dan sesudah promosi kesehatan Sadari. Tahapan penelitian dimulai dengan mempersiapkan materi promosi kesehatan mengenai Sadari, setelah itu membuat sebuah akun instagram dengan nama (a)ayolakukansadari untuk promosi kesehatan, dan mempersiapkan alat ukur pengetahuan, sikap, persepsi kegunaan teknologi mengenai Sadari berupa kuesioner.
Responden mengisi kuesioner pretest terlebih dahulu sebelum dilakukan intervensi. Intervensi yang diberikan yaitu promosi kesehatan mengenai Sadari menggunakan media sosial instagram dengan akun yang telah dipersiapkan sebelumnya. Materi yang diberikan berupa info grafis (gambar, teks dan video) terkait Sadari yang diposting setiap hari, dengan frekuensi posting 1 
Tabel 3a. Distribusi Frekuensi Sikap Responden Sebelum dan Sesudah Promosi Kesehatan Menggunakan Instagram

\begin{tabular}{|c|c|c|c|c|c|c|c|c|c|c|c|}
\hline \multirow[b]{2}{*}{ No. } & \multirow[b]{2}{*}{ Pernyataan } & \multicolumn{5}{|c|}{ Pretest } & \multicolumn{5}{|c|}{ Posttest } \\
\hline & & $\begin{array}{c}\text { SS } \\
(\%)\end{array}$ & $\begin{array}{c}S \\
(\%)\end{array}$ & $\begin{array}{c}\text { KS } \\
(\%)\end{array}$ & $\begin{array}{l}\text { TS } \\
(\%)\end{array}$ & $\begin{array}{l}\text { STS } \\
\text { (\%) }\end{array}$ & $\begin{array}{c}\text { SS } \\
(\%)\end{array}$ & $\begin{array}{c}S \\
(\%)\end{array}$ & $\begin{array}{l}\text { KS } \\
(\%)\end{array}$ & $\begin{array}{c}\text { TS } \\
(\%)\end{array}$ & $\begin{array}{l}\text { STS } \\
(\%)\end{array}$ \\
\hline 1. & $\begin{array}{l}\text { Sebagai seorang wanita } \\
\text { saya harus selalu } \\
\text { waspada terhadap } \\
\text { kelainan payudara }\end{array}$ & 90,2 & 9,8 & - & - & - & 88,5 & 8,2 & 3,3 & - & - \\
\hline 2. & $\begin{array}{l}\text { Saya akan menjaga } \\
\text { pola hidup sehat agar } \\
\text { terhindar dari kanker } \\
\text { payudara }\end{array}$ & 80,3 & 19,7 & - & - & - & 80,3 & 18 & 1,6 & - & - \\
\hline 3. & $\begin{array}{l}\text { Saya akan menjauh } \\
\text { dari penderita kanker } \\
\text { payudara karena saya } \\
\text { takut tertular olehnya }\end{array}$ & - & 8,2 & 26,2 & 21,3 & 44,3 & 1,6 & 1,6 & 8,2 & 24,6 & 63,9 \\
\hline 4. & $\begin{array}{l}\text { Sadari hanya dilakukan } \\
\text { oleh perempuan yang } \\
\text { sudah menikah }\end{array}$ & - & - & 18 & 37,7 & 44,3 & - & - & 8,2 & 29,5 & 62,3 \\
\hline 5. & $\begin{array}{l}\text { Saya akan melakukan } \\
\text { sadari jika sudah muncul } \\
\text { keluhan seperti rasa } \\
\text { nyeri }\end{array}$ & 6,6 & 19,7 & 18 & 31,1 & 24,6 & 11,5 & 6,6 & 19,7 & 27,9 & 34,4 \\
\hline 6. & $\begin{array}{l}\text { Saya tidak perlu } \\
\text { khawatir terkena kanker } \\
\text { payudara jika mengalami } \\
\text { benjolan yang terasa } \\
\text { nyeri di area payudara }\end{array}$ & - & - & 8,2 & 26,2 & 65,6 & 1,6 & 3,3 & 11,5 & 23 & 60,7 \\
\hline
\end{tabular}

kali sehari. Jarak antara pretest dengan intervensi adalah 1 hari. Intervensi dalam penelitian dilakukan selama 10 hari dengan pemberian postingan yang bisa dilihat responden dimana saja responden berada. Responden diwajibkan memberi tanda "love" dan atau komentar pada setiap postingan untuk mengetahui responden sudah melihat postingan tersebut. Tahapan terakhir yaitu posttest untuk mengukur tingkat pengetahuan, sikap, dan persepsi kegunaan responden mengenai Sadari setelah dilakukan intervensi. Pengukuruan posttest dilakukan 1 hari setelah intervensi. Rentang waktu intervensi dilakukan dalam waktu relatif singkat untuk menjaga kualitas informasi. Selain itu sebelum intervensi dimulai, responden telah menandatangani kesepakatan untuk tidak mencari infomasi terkait Sadari dan kanker payudara dari sumber selain postingan selama10 hari intervensi berlangsung .

\section{HASIL}

Jumlah responden yang ada dalam penelitian berjumlah 61 orang yang terdiri dari mahasiswi fakultas ekonomi sebanyak 34 orang dan fakultas pertanian sebanyak 27 orang. Responden yang menggunakan instagram terdiri dari angkatan 2015 sampai 2018. Kelompok umur responden yang paling banyak berada pada usia rentang 1620 tahun. Frekuensi tertinggi responden mulai menggunakan media sosial instagram dimulai pada tahun 2015 (Tabel 1).

Pada saat pretest dan posttest terjadi perubahan skor pengetahuan responden. Pertanyaan mengenai definisi Sadari memiliki skor pretest $44,3 \%$ orang yang menjawab benar, setelah dilakukan intervensi berupa promosi kesehatan meningkat menjadi $72,1 \%$. Selain itu juga terjadi peningkatan pengetahun responden pada pertanyaan waktu untuk mulai melakukan Sadari pada pretest $42,6 \%$ menjadi $65,5 \%$ responden menjawab pertanyaan 
Tabel 3a. Distribusi Frekuensi Sikap Responden Sebelum dan Sesudah Promosi Kesehatan Menggunakan Instagram

\begin{tabular}{|c|c|c|c|c|c|c|c|c|c|c|c|}
\hline \multirow[b]{2}{*}{ No. } & \multirow[b]{2}{*}{ Pernyataan } & \multicolumn{5}{|c|}{ Pretest } & \multicolumn{5}{|c|}{ Posttest } \\
\hline & & $\begin{array}{c}\text { SS } \\
(\%)\end{array}$ & $\begin{array}{c}\mathbf{S} \\
(\%)\end{array}$ & $\begin{array}{l}\text { KS } \\
(\%)\end{array}$ & $\begin{array}{c}\text { TS } \\
(\%)\end{array}$ & $\begin{array}{l}\text { STS } \\
(\%)\end{array}$ & $\begin{array}{c}\text { SS } \\
(\%)\end{array}$ & $\begin{array}{c}\mathbf{S} \\
(\%)\end{array}$ & $\begin{array}{c}\text { KS } \\
(\%)\end{array}$ & $\begin{array}{c}\text { TS } \\
(\%)\end{array}$ & $\begin{array}{l}\text { STS } \\
(\%)\end{array}$ \\
\hline 7. & $\begin{array}{l}\text { Menurut saya media } \\
\text { sosial Instagram adalah } \\
\text { alternatif paling praktis } \\
\text { untuk memperoleh } \\
\text { informasi mengenai } \\
\text { Sadari }\end{array}$ & 21,3 & 65,6 & 11,5 & 1,6 & - & 52,5 & 39,3 & 8,2 & - & - \\
\hline 8. & $\begin{array}{l}\text { Menurut saya sangat } \\
\text { perlu untuk bergabung } \\
\text { dalam grup Instagram } \\
\text { tentang kesehatan } \\
\text { khususnya mengenai } \\
\text { Sadari }\end{array}$ & 36,1 & 52,5 & 8,2 & 3,3 & - & 57,4 & 31,1 & 11,5 & - & - \\
\hline 9. & $\begin{array}{l}\text { Menurut saya sangat } \\
\text { penting untuk mencari } \\
\text { tahu informasi kesehatan } \\
\text { khususnya Sadari } \\
\text { setiap harinya di akun } \\
\text { Instagram saya }\end{array}$ & 36,1 & 44,3 & 18,0 & 1,6 & - & 47,5 & 41,0 & 11,5 & - & - \\
\hline 10. & $\begin{array}{l}\text { Saya langsung mencari } \\
\text { informasi melalui } \\
\text { akun Instagram jika } \\
\text { menemukan benjolan } \\
\text { pada payudara saya }\end{array}$ & 37,7 & 45,9 & 11,5 & 4,9 & - & 47,5 & 42,6 & 9,8 & - & - \\
\hline
\end{tabular}

dengan benar. Pertanyaan mengenai tujuan dari memencet puting payudara saat melakukan Sadari yaitu sebanyak $54,1 \%$ meningkat menjadi $80,3 \%$ menjawab benar (Tabel 2). Distribusi sikap responden juga mengalami perubahan setelah dilakukan pretest dan posttest. Sebanyak $44,3 \%$ responden sangat tidak setuju dengan pernyataan saya akan menjauh dari penderita kanker payudara karena saya takut tertular, meningkat menjadi $63,9 \%$ setelah posttest. Pernyataan mengenai Sadari hanya dilakukan oleh perempuan yang sudah menikah juga mengalami peningkatan skor, dimana $44,3 \%$ yang menyata- kan sangat tidak setuju menjadi $62,3 \%$. Selanjutnya pernyataan saya akan melakukan pemeriksaan Sadari secara berurutan sesuai tahapannya, meningkat dari $42,6 \%$ yang menyatakan sangat setuju menjadi $67,2 \%$ (Tabel 3). Persepsi kegunaan teknologi juga mengalami perubahan skor pada saat pretest dan posttest. Perubahan skor tertinggi terjadi pada pernyataan saya merasa mudah memperoleh informasi mengenai Sadari melalui instagram, yaitu sebanyak $26,2 \%$ menyatakan sangat setuju meningkat menjadi $65,6 \%$ setelah posttest. Pernyataan menurut saya instagram dapat mengingatkan saya untuk melakukan Sadari secara teratur, 26,2\% menyatakan sangat setuju dan meningkat menjadi $65,6 \%$ saat posttest (Tabel 4).

Berdasarkan Tabel 5 diketahui bahwa ratarata skor variabel pengetahuan responden sebelum intervensi yaitu 6,74 dengan standar deviasi 1,436 , sedangkan rata-rata pengetahuan responden setelah intervensi yaitu 7,38 dengan standar deviasi 1,356. Berdasarkan hasil analisis uji wilcoxon diperoleh nilai $\mathrm{p}$ value $<0,05(\mathrm{p}=0,003)$ dapat disimpulkan bahwa terdapat perbedaan skor ratarata pengetahuan Sadari responden sebelum dan sesudah intervensi menggunakan media sosial instagram. Rata-rata skor variabel sikap responden sebelum intervensi yaitu 48,15 dengan standar deviasi 3,974, sedangkan rata-rata sikap responden setelah intervensi yaitu 49,46 dengan standar deviasi 4,857. Berdasarkan hasil analisis uji wilcoxon diperoleh nilai $\mathrm{p}$ value $<0,05(\mathrm{p}=0,01)$ dapat 
Tabel 4a. Distribusi Persepsi Kegunaan Teknologi Responden Sebelum dan Sesudah Promosi Kesehatan Menggunakan Instagram

\begin{tabular}{|c|c|c|c|c|c|c|c|c|c|c|c|}
\hline \multirow[b]{2}{*}{ No. } & \multirow[b]{2}{*}{ Pernyataan } & \multicolumn{5}{|c|}{ Pretest } & \multicolumn{5}{|c|}{ Posttest } \\
\hline & & $\begin{array}{c}\text { SS } \\
(\%)\end{array}$ & $\begin{array}{c}S \\
(\%)\end{array}$ & $\begin{array}{c}\text { KS } \\
(\%)\end{array}$ & $\begin{array}{c}\text { TS } \\
(\%)\end{array}$ & $\begin{array}{l}\text { STS } \\
(\%)\end{array}$ & $\begin{array}{c}\text { SS } \\
(\%)\end{array}$ & $\begin{array}{c}\mathbf{S} \\
(\mathbf{\%})\end{array}$ & $\begin{array}{c}\text { KS } \\
(\%)\end{array}$ & $\begin{array}{c}\text { TS } \\
(\%)\end{array}$ & $\begin{array}{l}\text { STS } \\
(\%)\end{array}$ \\
\hline 1. & $\begin{array}{l}\text { Saya merasa mudah } \\
\text { memperoleh informasi } \\
\text { mengenai Sadari melalui } \\
\text { Instagram }\end{array}$ & 26,2 & 54,1 & 11,5 & 8,2 & - & 65,6 & 26,2 & 8,2 & - & - \\
\hline 2. & $\begin{array}{l}\text { Saya merasa informasi } \\
\text { tentang Sadari di } \\
\text { Instagram sesuai } \\
\text { keinginan dan kebutuhan } \\
\text { saya }\end{array}$ & 24,6 & 49,2 & 18,0 & 6,6 & 1,6 & 60,7 & 32,8 & 6,6 & - & - \\
\hline 3. & $\begin{array}{l}\text { Menurut saya Instagram } \\
\text { adalah media sosial yang } \\
\text { tepat untuk memperoleh } \\
\text { informasi mengenai } \\
\text { Sadari }\end{array}$ & 26,2 & 60,7 & 9,8 & 3,3 & - & 59,0 & 34,4 & 6,6 & - & - \\
\hline 4. & $\begin{array}{l}\text { Media Sosial Instagram } \\
\text { tidak membantu saya } \\
\text { memperoleh informasi } \\
\text { mengenai Sadari }\end{array}$ & - & 3,3 & 8,2 & 62,3 & 26,2 & - & - & 6,6 & 31,1 & 62,3 \\
\hline 5. & $\begin{array}{l}\text { Menurut saya media } \\
\text { sosial Instagram dapat } \\
\text { mengingatkan saya } \\
\text { untuk melakukan deteksi } \\
\text { dini Sadari secara teratur }\end{array}$ & 26,2 & 59 & 11,5 & 3,3 & - & 65,6 & 26,2 & 8,2 & - & - \\
\hline 6. & $\begin{array}{l}\text { Saya merasa sumber } \\
\text { informasi mengenai } \\
\text { Sadari di Instagram tidak } \\
\text { dapat dipercaya }\end{array}$ & - & 3,3 & 29,5 & 54,1 & 13,1 & - & 3,3 & 9,8 & 41,0 & 45,9 \\
\hline 7. & $\begin{array}{l}\text { Menurut saya media } \\
\text { sosial Instagram adalah } \\
\text { alternatif paling praktis } \\
\text { untuk memperoleh } \\
\text { informasi mengenai } \\
\text { Sadari }\end{array}$ & 21,3 & 65,6 & 11,5 & 1,6 & - & 52,5 & 39,3 & 8,2 & - & - \\
\hline
\end{tabular}

disimpulkan bahwa terdapat perbedaan skor ratarata sikap mengenai Sadari responden sebelum dan sesudah intervensi. Rata-rata skor variabel persepsi kegunaan teknologi media sosial instagram responden sebelum intervensi yaitu 40,52 dengan standar deviasi 5,611, sedangkan rata-rata persepsi kegunaan teknologi responden setelah intervensi yaitu 44,70 dengan standar deviasi 5,123 . Berdasarkan hasil analisis uji wilcoxon diperoleh nilai $\mathrm{p}$ value $<0,05(\mathrm{p}=0,000)$ dapat disimpulkan bahwa terdapat perbedaan skor rata-rata persepsi kegunaan teknologi media sosial instagram respon- den sebelum dan sesudah intervensi.

\section{PEMBAHASAN}

Skor rata-rata pengetahuan Sadari mahasiswi mengalami peningkatan sebelum dan sesudah intervensi. Hasil ini sejalan dengan penelitian Sari yang melakukan promosi kesehatan tentang $D a$ gusibu (Cara Tepat Penggunaan Obat) melalui media sosial instagram pada mahasiswa Universitas Muhammadiyah Purwokerto. Hasilnya terjadi peningkatan pengetahuan mahasiswa dengan $p$ value $0,002(\mathrm{p}<0,05){ }^{8}$ Peningkatan pengetahuan 
Tabel 4b. Distribusi Persepsi Kegunaan Teknologi Responden Sebelum dan Sesudah Promosi Kesehatan Menggunakan Instagram

\begin{tabular}{|c|c|c|c|c|c|c|c|c|c|c|c|}
\hline \multirow[b]{2}{*}{ No. } & \multirow[b]{2}{*}{ Pernyataan } & \multicolumn{5}{|c|}{ Pretest } & \multicolumn{5}{|c|}{ Posttest } \\
\hline & & $\begin{array}{c}\text { SS } \\
(\%)\end{array}$ & $\begin{array}{c}\mathrm{S} \\
(\%)\end{array}$ & $\begin{array}{l}\text { KS } \\
(\%)\end{array}$ & $\begin{array}{c}\text { TS } \\
(\%)\end{array}$ & $\begin{array}{l}\text { STS } \\
(\%)\end{array}$ & $\begin{array}{c}\text { SS } \\
(\%)\end{array}$ & $\begin{array}{c}S \\
(\%)\end{array}$ & $\begin{array}{l}\text { KS } \\
(\%)\end{array}$ & $\begin{array}{c}\text { TS } \\
(\%)\end{array}$ & $\begin{array}{l}\text { STS } \\
(\%)\end{array}$ \\
\hline 8. & $\begin{array}{l}\text { Menurut saya sangat } \\
\text { perlu untuk bergabung } \\
\text { dalam grup Instagram } \\
\text { tentang kesehatan } \\
\text { khususnya mengenai } \\
\text { Sadari }\end{array}$ & 36,1 & 52,5 & 8,2 & 3,3 & - & 57,4 & 31,1 & 11,5 & - & - \\
\hline 9. & $\begin{array}{l}\text { Menurut saya sangat } \\
\text { penting untuk mencari } \\
\text { tahu informasi kesehatan } \\
\text { khususnya Sadari } \\
\text { setiap harinya di akun } \\
\text { Instagram saya }\end{array}$ & 36,1 & 44,3 & 18,0 & 1,6 & - & 47,5 & 41,0 & 11,5 & - & - \\
\hline 10. & $\begin{array}{l}\text { Saya langsung mencari } \\
\text { informasi melalui } \\
\text { akun Instagram jika } \\
\text { menemukan benjolan } \\
\text { pada payudara saya }\end{array}$ & 37,7 & 45,9 & 11,5 & 4,9 & - & 47,5 & 42,6 & 9,8 & - & - \\
\hline
\end{tabular}

Tabel 5. Variabel Pengetahuan, Sikap, dan Persepsi Kegunaan Teknologi Sebelum dan Sesudah Intervensi

\begin{tabular}{lccc}
\hline \multicolumn{1}{c}{ Variabel } & Mean \pm SD & Min-Max & p value \\
\hline Pengetahuan & & & \\
$\quad$ Pretest & $6.74 \pm 1.436$ & $4-10$ & 0.003 \\
$\quad$ Posttest & $7.38 \pm 1.356$ & $4-10$ & \\
Sikap & & & \\
$\quad$ Pretest & $48.15 \pm 3.974$ & $37-55$ & 0.01 \\
$\quad$ Posttest & $49.46 \pm 4.857$ & $33-55$ & \\
Persepsi Kegunaan Teknologi & & & \\
$\quad$ Pretest & $40.52 \pm 5.611$ & $20-50$ & 0.000 \\
$\quad$ Posttest & $44.70 \pm 5.123$ & $29-50$ & \\
\hline
\end{tabular}

tertinggi tampak pada pertanyaan mengenai definisi Sadari, tujuan dari pemeriksaan putting, dan waktu untuk pemeriksaan Sadari. Informasi mengenai topik-topik tersebut dapat diperoleh mahasiswi tidak hanya dari postingan gambar, tetapi juga dari postingan video.

Hasil penelitian yang dilakukan oleh Silalahi et al menunjukkan bahwa pendidikan kesehatan melalui audiovisual efektif dalam meningkatkan perilaku wanita dalam melakukan pemeriksaan Inspeksi Visual dengan Asam Asetat (IVA). ${ }^{12}$ Menurut Notoatmodjo, pengetahuan tercipta dari hasil penginderaan, yaitu indera penglihatan, pendengaran, penciuman, rasa, dan raba. Sebagian besar pengetahuan diperoleh melalui indera peng- lihatan dan pendengaran. Penyampaian informasi melalui gambar edukatif, penerima pesan akan meningkatkan respon emosional dan peningkatan minat belajar dengan topik pembelajaran yang spesifik. Perumusan gambar edukatif yang baik akan berimplikasi positif terhadap penerima pesan pada segmentasi usia. ${ }^{13}$ Begitu juga dengan hasil penelitian Herawati bahwa promosi kesehatan dengan video efektif meningkatkan pengetahuan tentang kanker payudara dan keterampilan Deteksi Dini Kanker Payudara (Sadari) pada remaja putri. Media video merupakan cara pemberian informasi yang sangat baik karena membuat mahasiswa fokus dengan materi promosi akibat adanya gerakan yang membuat mata fokus kearah tersebut. 
Oleh karena semakin banyak indera yang berperan dalam proses penerimaan pesan maka penerimaan pesan akan semakin mudah ditangkap. Kegiatan seperti pemeriksaan payudara sendiri lebih mudah dipahami jika langsung melihat prakteknya dibandingkan hanya melihat potongan gambargambarnya saja. ${ }^{14}$

Terdapat perbedaan skor rata-rata sikap mengenai Sadari mahasiswi sebelum dan sesudah intervensi. Penelitian Althunayan et al di Arab Saudi menyatakan bahwa lebih dari 50\% responden yang menerima pesan promosi kesehatan gigi dan mulut melalui media sosial instagram memiliki sikap yang positif. ${ }^{9}$ Sejalan dengan itu, hasil penelitian Alessandro et al, menyimpulkan bahwa promosi kesehatan dengan topik "ASI dan Menyusui" melalui media sosial instagram mampu mengubah persepsi dan membangun dukungan kelompok untuk ibu menyusui di Kanada. Penelitian ini memperhatikan jumlah postingan gambar, tanda pagar (hashtag), dan diskusi yang terjadi terkait ASI dan menyusui. ${ }^{10}$

Hasil penelitian ini menunjukan peningkatan skor sikap mahasiswi dengan jawaban sangat setuju mengenai pernyataan tidak akan menghindar dari penderita kanker payudara, sikap untuk melakukan Sadari sebagai upaya deteksi dini, dan akan melakukan Sadari secara berurutan sesuai dengan tahapannya. Berdasarkan hasil penelitian juga diketahui bahwa 97,7\% responden tidak bosan pada materi yang disampaikan karena desain gambar dan postingan yang menarik. Instagram memiliki fitur utama berbagi gambar dan video sehingga dibutuhkan desain yang menarik. Studi yang dilakukan Al-Eisa et al, menyimpulkan bahwa penggunaan instagram dalam program aktifitas fisik di rumah efektif untuk meningkatkan motivasi, memperkuat kepatuhan, dan mempertahankan tingkat aktivitas fisik yang tepat. Postingan berupa gambar dan video disyaratkan harus atraktif dan efektif. Penelitian ini dilakukan pada 54 mahasiswi studi S1 di King Saud University, Riyadh dengan metode kuasi eksperimen. ${ }^{15}$

Sikap merupakan suatu kecenderungan yang dimiliki seseorang untuk merespon baik secara positif ataupun negatif suatu objek tertentu melalui suatu persuasi maupun panutan seseorang atau kelompok. Perubahan sikap pada dasarnya dipengaruhi oleh faktor pengetahuan dan ke- yakinan/kepercayaan yang didapatkan dari hasil penginderaan salah satunya didapatkan melalui pendidikan atau proses belajar. ${ }^{16}$ Sikap positif ini juga tampak dari hasil kuesioner evaluasi yang menemukan bahwa 98,3\% responden bersedia untuk mengikuti (follow) akun @ayolakukansadari dan bersedia menerima satu postingan setiap harinya. Sikap memiliki tingkatan, yaitu menerima, yang diartikan kemauan seseorang dalam menerima stimulus yang diberikan. Selanjutnya menanggapi yang diartikan sebagai pemberian jawaban atau tanggapan terhadap pertanyaan atau objek yang dihadapi. Kemudian dilanjutkan dengan menghargai dengan memberikan nilai yang positif terhadap objek atau stimulus yang diberikan. Setelah itu bertanggung jawab dengan sikap yang dipilihnya. ${ }^{13}$

Terdapat perbedaan skor rata-rata persepsi kegunaan teknologi mahasiswi sebelum dan sesudah intervensi. Terjadi peningkatan pandangan responden mengenai kemudahan dan kemanfaatan media sosial instagram sebagai media promosi kesehatan. Penelitian ini relevan dengan penelitian yang dilakukan Widodo et al, yang menyatakan bahwa adanya pengaruh persepsi kegunaan terhadap sikap penggunaan teknologi pada pengguna instagram di Indonesia. ${ }^{17}$ Penelitian ini dilakukan terhadap 100 sampel dan sebesar $81,76 \%$ yang memberikan tanggapan baik terhadap persepsi kegunaan. Hal ini menunjukkan bahwa instagram memiliki kegunaan atau manfaat yang baik bagi responden untuk mencari informasi. Berdasarkan hasil penelitian, juga terdapat peningkatan persepsi kegunaan teknologi mahasiswi sesudah promosi kesehatan Sadari, antara lain sangat setuju mengenai mudah memperoleh informasi Sadari di instagram. Menurut Jogiyanto, pemakai sistem teknologi akan menggunakan sistem jika pertama merasa bahwa sistem tesebut mudah digunakan. Jika seseorang merasa percaya bahwa sistem informasi mudah digunakan dan berguna, maka dia akan menggunakannya. ${ }^{18}$ Semakin mudah penggunaan suatu sistem teknologi maka semakin diyakini bahwa teknologi tersebut memberikan manfaat pada penggunanya.

Hal ini sejalan dengan penelitian Althunayan et al, dengan judul "Role of Social Media in Dental Health Promotion and Behavior Change in Qassim Province, Saudi Arabia". Diketahui 64\% 
responden menggunakan media sosial untuk mencari tahu mengenai kesehatan gigi dan mulut dan 40,9\% menggunakan media instagram. Alasan pemilihan media ini oleh responden adalah karena unsur kemudahan penggunaan dan akses. ${ }^{9} \mathrm{Pe}$ ningkatan persepsi kegunaan teknologi tertinggi sesudah promosi kesehatan Sadari juga terdapat pada pernyataan, sangat setuju instagram mengingatkan saya untuk melakukan deteksi dini Sadari secara teratur. Hasil ini dapat dimanfaatkan berbagai pihak untuk menggunakan media instagram sebagai sarana promosi kesehatan yang berkelanjutan agar pengguna tidak lupa untuk melakukan deteksi dini Sadari setiap bulannya.

Berdasarkan analisis kuesioner diketahui bahwa hal yang sangat menjadi perhatian oleh responden yaitu mengenai isi atau konten promosi kesehatan. Sehingga selain desain yang menarik, isi materi yang disampaikan harus diperhatikan pada promosi kesehatan melalui media sosial. Scharl et al, menyatakan bahwa isi atau konten adalah salah satu faktor kesuksesan dalam pesan promosi. Pesan dan media yang baik akan mempengaruhi kepercayaan (belief) konsumen terhadap isi pesan dengan munculnya sikap konsumen yang positif dan persepsi terhadap kemanfaatan, kemudahan, dan penggunaan. Isi pesan yang persuasif akan menarik perhatian konsumen sehingga memunculkan niat untuk berperilaku. ${ }^{19}$ Pentingnya isi dan desain materi promosi kesehatan Sadari dibuktikan dengan sebagian besar responden $(77,9 \%)$ membaca semua materi yang diberikan.

\section{KESIMPULAN DAN SARAN}

Terdapat perbedaan pengetahuan, sikap, dan persepsi kegunaan teknologi tentang Sadari pada mahasiswi non kesehatan di Universitas Andalas sebelum dan sesudah dilakukan promosi kesehatan menggunakan media sosial instagram. Media sosial instagram dapat dimanfaatkan sebagai media promosi kesehatan untuk meningkatkan pengetahuan dan sikap masyarakat agar mengetahui informasi mengenai kesehatan khususnya deteksi dini kanker payudara melalui Pemeriksaan Payudara Sendiri (Sadari). Disarankan untuk penelitian selanjutnya agar mengumpulkan peserta dalam satu ruangan ketika memberi postingan dan melakukan intervensi dalam kurun waktu yang lebih singkat untuk mengontrol kualitas data.
Penambahan pertanyaan mengenai preferensi postingan yang diminati responden berupa gambar, video, atau kombinasinya juga perlu dilakukan.

\section{UCAPAN TERIMA KASIH}

Penulis mengucapkan terimakasih dan memberikan penghargaan kepada Fakultas Kesehatan Masyarakat Universitas Andalas yang telah mendanai penelitian ini melalui dana DIPA.

\section{DAFTAR PUSTAKA}

1. Kementerian Kesehatan Republik Indonesia. Infodatin Kanker. Jakarta: Departemen Kesehatan RI; 2017.

2. Latest Global Cancer Data: Cancer Burden Rises to 18.1 Million New Cases and 9.6 Million Cancer Deaths in 2018 [Press Release]. WHO IARC; 2018.

3. Pusat Data dan Informasi Kementerian Kesehatan RI. Bulan Peduli Kanker. In: Indonesia KKR, editor. Jakarta; 2015.

4. Rahmi H. Pengaruh Promosi Kesehatan Melalui "Instagram" terhadap Pengetahuan dan Sikap "Sadari" pada Mahasiswi Fakultas Kesehatan Masyarakat Universitas Andalas [Skripsi]: Padang: FKM Universitas Andalas; 2017.

5. Putri O. Kualitas Hidup Pasien Kanker Payudara di Poliklinik Bedah RSUP Dr. M. Djamil Padang Tahun 2017 [Skripsi]. Padang: FK Universitas Andalas; 2017.

6. Mulyani NS, Nuryani. Kanker Payudara dan PMS pada Kehamilan. Yogyakarta: Nuha Medika; 2013.

7. ComScore Announces Launch of MMX MultiPlatform, As Well As Major Enhancements to Mobile Metrix in Indonesia with Introduction of Mobile Consumer Panel Data [Press Release]; 2017.

8. Sari RP. Efektivitas Penggunaan Media Sosial Berupa Facebook dan Instagram Untuk Meningkatkan Pengetahuan Mahasiswa Non Kesehatan Tentang Dagusibu di Universitas Muhammadiyah Purwokerto [Skripsi]. Purwokerto: Universitas Muhammadiyah Purwokerto; 2017.

9. Althunayan A, Alsalhi R, Elmoazen R. Role of Social Media In Dental Health Promotion and Behavior Change In Qassim Province, Saudi 
Arabia. International Journal of Medical and Health Research. 2018;4(2):98-103.

10. Alessandro R. Marcon et al. Protecting, Promoting, and Supporting Breastfeeding on Instagram. Wiley Maternal and Child Nutrition Journal. 2018;15(1):1-12.

11. Universitas Andalas. Available at: https:// www.unand.ac.id/id/sejarah.html.

12. Silalahi V, Lismidiati W, Hakimi M. Efektivitas Audio Visual dan Booklet sebagai Media Edukasi untuk Meningkatkan Perilaku Skrining IVA. Media Kesehatan Masyarakat Indonesia. 2018;14(3):304-315.

13. Notoatmojo S. Ilmu Perilaku Kesehatan. Jakarta: Rinneka Cipta; 2014.

14. Herawati N, M Damris, Marshal J. Studi Perbandingan Promosi Kesehatan Antara Leaflet dengan Video terhadap Pengetahuan tentang Kanker Payudara dan Keterampilan Deteksi Dini Kanker Payudara (Sadari) pada Remaja Putri di Jurusan Kebidanan Poltekes Jambi Tahun 2016. Tekno Pedagogi.
2017;7(2).

15. Einas Al Eisa et al. Effect of Motivation by "Instagram" on Adherence to Physical Activity among Female College Students. BioMed Research International. 2016;(10):1-6.

16. Kholid A. Promosi Kesehatan. Jakarta: Rajawali Pers; 2014.

17. Widodo A, Putri ASA. Pengaruh Persepsi Kegunaan dan Persepsi Kemudahan Penggunaan terhadap Sikap Penggunaan Teknologi pada Pengguna Instagram di Indonesia (Studi pada Followers Akun Kementerian Pariwisata @indotravel). Jurnal Sekretaris dan Administrasi Bisnis. 2017;1(1):18-26.

18. Jogiyanto. Sistem Informasi Keperilakuan. Yogyakarta: Penerbit ANDI; 2007.

19. Scharl A, Dickinger A, Murphy J. Diffusion and Success Factors of Mobile Marketing. Electronic Commerce Research and Applications. 2005;4(2):159-173. 